\title{
EDUCAÇÃO FÍSICA E SAÚDE: APROXIMAÇÕES COM A "CLÍNICA AMPLIADA"I
}

\author{
DRA. FABIANA FERNANDES DE FREITAS \\ Escola de Educação Física e Esporte, Universidade \\ de São Paulo (São Paulo - São Paulo - Brasil) \\ E-mail: fabifreitas@usp.br
}

DRA. YARA MARIA DE CARVALHO

Escola de Educação Física e Esporte, Universidade de São Paulo (São Paulo - São Paulo - Brasil)

E-mail: yaramc@usp.br

\section{MS. VALÉRIA MONTEIRO MENDES \\ Escola de Educação Física e Esporte, Universidade de São Paulo (São Paulo - São Paulo - Brasil) \\ E-mail: valeriamm@usp.br}

\begin{abstract}
RESUMO
Este ensaio apresenta algumas reflexões acerca da educação física do ponto de vista da formação profissional e do trabalho em saúde, tendo como objetivo relacionar estes aspectos ao referencial teórico-conceitual e metodológico da Clínica Ampliada. Formação e trabalho remetem a uma inserção e um desenvolvimento singular da educação física no campo da saúde, inclusive no âmbito das políticas públicas. Entretanto, observa-se ausência de fundamentação na formação e intervenção profissional para além da perspectiva biologicista. Nesse sentido, a Clínica Ampliada pode ser um contraponto, ela oferece subsídios no diálogo com outras profissões, nas ações orientadas por relações mais horizontais e na aproximação entre profissional específico, serviço de saúde e usuários do SUS.
\end{abstract}

PALAVRAS-CHAVE: Educação fisica; clínica ampliada; formação profissional; trabalho em saúde.

I. $\bigcirc$ presente trabalho contou com apoio financeiro da Capes, vinculado ao projeto "Políticas de Formação em Educação Física e Saúde Coletiva"; Edital 24/20 I0; Processo 06/6 320 -9. Não houve conflito de interesses para a realização do presente estudo. 
É cada vez mais perceptível a ampliação do campo de intervenção e interlocução denominado educação física na saúde, especialmente nos serviços de atenção básica. Na dimensão das políticas, podem ser exemplos a Política Nacional de Promoção da Saúde (PNPS) publicada em 2006a, que contempla ações relativas às atividades físicas/práticas corporais (af/pc); a Política Nacional de Práticas Integrativas e Complementares (PNPIC) também de 2006, que destaca particularmente as práticas corporais relacionadas à Medicina Tradicional Chinesa; os processos de estruturação e implementação dos Núcleos de Apoio de Saúde à Família (NASF)² a partir de 2008, que formalizam a participação do profissional específico junto às equipes de apoio que atuam nas Unidades Básicas de Saúde (UBS); e, mais recentemente, em 20 I I, o Programa Academia da Saúde, que busca contribuir para a promoção da saúde da população por meio da implantação de centros de af/pc, de lazer e modos de vida saudáveis denominados de Polos da Academia da Saúde.

Percebe-se, assim, uma institucionalização dos conteúdos e das ações da educação física na atenção básica à saúde, o que sugere uma mudança nos modos de fazer o trabalho em saúde e maior articulação com o campo. Nesse sentido, aproximações com o conceito de "saúde ampliada" podem contribuir para direcionar o olhar do profissional da área específica para compor com outros profissionais no trabalho multidisciplinar; questionar as relações de poder entre profissionais e usuários; e não perder de vista os princípios do Sistema Único de Saúde (SUS): a universalidade, que garante o direito à saúde e o acesso ao conjunto de ações e serviços oferecidos pelo sistema de saúde; a integralidade, que pressupõe tanto o reconhecimento das distintas dimensões relacionadas com o processo saúde-doença, quanto à prestação continuada do conjunto de ações e serviços com o propósito de assegurar promoção, proteção, cura e reabilitação para sujeitos e coletividades; e a equidade, que diz respeito à prioridade na oferta de ações e serviços aos segmentos populacionais que apresentam maiores chances de adoecer ou morrer em função de questões socioeconômicas, como a distribuição desigual de renda, de bens e serviços (VASCONCELOS; PASCHE, 2007).

2. É a portaria $N^{\circ} 154$, de 24 de janeiro de 2008, que faz referência ao NASF. Dois tipos de núcleos podem ser implementados e incluem o profissional de Educação Física. O NASF I deve ser formado por cinco profissionais, no mínimo, de diferentes formações: Assistente Social; Profissional de Educação Física; Farmacêutico; Fisioterapeuta; Fonoaudiólogo; Médico Acupunturista; Médico Ginecologista; Médico Homeopata; Médico Pediatra; Médico Psiquiatra; Nutricionista; Psicólogo e Terapeuta Ocupacional. O NASF 2 só pode ser implementado em municípios com densidade populacional abaixo de 10 habitantes por quilômetro quadrado, e deverá ser composto por três profissionais, no mínimo, de diferentes formações: Assistente Social; Profissional de Educação Física; Farmacêutico; Fisioterapeuta; Fonoaudiólogo; Nutricionista; Psicólogo e Terapeuta Ocupacional. 
Diante desses desafios algumas questões são prementes: como desenvolver o trabalho em saúde na dimensão da "saúde ampliada"? Qual é a formação que responde às necessidades de saúde que se apresentam via o serviço de atenção básica à saúde? Em que medida esse referencial teórico-conceitual e metodológico pode orientar a formação e o trabalho do profissional na saúde?

Responder a estas questões passa por mais de um caminho. Um deles é justamente buscar fundamentação que dê suporte e instigue os profissionais a ressignificar e reinventar as práticas de saúde. Outro caminho é a intervenção, experimentar as relações entre profissionais, serviços e usuários. A Clínica Ampliada (CAMPOS, 2000, 2003; CUNHA, 2007) é um referencial na saúde coletiva que atua nos dois planos, formação e intervenção, à medida que elabora linhas teóricas e também estimula a construção coletiva que se expressa e se potencializa nos modos de fazer o trabalho em saúde.

Neste sentido, diferentes núcleos de saberes - medicina, psicologia, fisioterapia, terapia ocupacional, enfermagem e nutrição - têm desenvolvido interlocuções com a Clínica Ampliada, visando propor intervenções para além dos modelos objetivadores da saúde (ONOCKO CAMPOS, 2003; MALFITANO, 2005; SANTOS; ASSIS, 2006; PINTO, 2007; GARIGLIO; RADICCHI, 2008; NASCIMENTO; OLIVEIRA, 20I0; DEMÉTRIO et al., 20 I I; MATUMOTO et al., 20 l I). Contudo, tal movimento é pouco discutido na educação física. O único trabalho encontrado que faz essa relação com a Clínica Ampliada é o de MENDES (20 / 3), , que investigou uma forma de "experimentação" da teoria a partir de um projeto de intervenção com práticas corporais para usuários de um Centro de Saúde Escola com vistas a problematizar a participação do profissional específico na atenção básica, considerando o distanciamento entre formação e intervenção em relação ao serviço.

É nesta direção que este ensaio objetiva desenvolver essas duas questões formação e intervenção -, que mantêm estreita relação com o processo de recomposição das práticas de saúde proposto pela Clínica Ampliada. A escolha do tema justifica-se pela necessidade de se chamar a atenção para o que tem sido enfatizado na educação física do ponto de vista acadêmico; e, nessa linha, repensar a intervenção do profissional específico a partir da teoria da Clínica Ampliada, tendo como referência seu método correspondente, o "método da roda". Assim, a estrutura e a metodologia deste ensaio reafirmam a exigência colocada aos profissionais de

3. Trata-se de uma dissertação de mestrado defendida recentemente no programa de pós-graduação da EEEFE-USP. Parte desse estudo foi apresentada no I Seminário Internacional sobre Potencialidades e Inovações nos Processos de Trabalho em Saúde. Brasília, 26 a 28 de abril de 2012. MENDES, V. M.; CARVALHO, Y. M. As práticas corporais e a "clínica ampliada": uma experiência voltada à produção de saúde no Centro de Saúde Escola (CSE) Geraldo de Paula Souza da Faculdade de Saúde Pública/USP. 
saúde pela teoria que o orienta, qual seja: ressignificar a própria relação entre o problema de pesquisa e a metodologia de investigação.

\section{FORMAÇÃO PROFISSIONAL: A SAÚDE EM QUESTÃO}

A graduação na área da saúde, da qual a educação física é parte e exemplo, não prioriza a integração entre ensino e trabalho e também não está

[...] voltada para uma formação teórico-conceitual e metodológica que potencialize competências para a integralidade, onde se inclui o enfretamento das necessidades de saúde da população e de desenvolvimento do sistema de saúde (CARVALHO; CECCIM, 2007, p. I37).

A fundamentação que tem direcionado a formação dos profissionais de saúde, segundo Ceccim e Feuerwerker (2004), é de abordagem biologicista, medicalizante e procedimento-centrada. Entretanto, esse modelo hegemônico vem acumulando questionamentos para além da saúde coletiva, originando propostas de humanização e integralidade no cuidado em saúde, conforme destaca Ayres (2004), uma vez que "[...] as práticas de saúde contemporâneas estão passando por uma importante crise em sua história" (AYRES, 2004, p. 16), com repercussões no processo de reorientação profissional que envolve docentes e estudantes universitários, profissionais da saúde e usuários do SUS. ${ }^{4}$ São iniciativas que respondem ao desafio de produzir outros caminhos no que se refere à formação e educação em saúde.

Campos (2000) indica que o modelo tradicional de prestar assistência à saúde está em esgotamento, haja vista os limites de eficácia (baixo impacto) e de eficiência (custos elevados). Sinaliza para a necessidade de se rever os conhecimentos e as práticas em saúde, tendo como pano fundo o cenário contemporâneo. Reconhece também que já há um movimento crescente de transformação no mundo em relação à organização e à prestação de serviços de saúde, que inclui:

a valorização da atenção básica com capacidade para resolver problemas individuais e coletivos; a ampliação das ações de prevenção e promoção; a rearticulação dos serviços especializados e de alta complexidade segundo diretrizes de humanização e de adoção de práticas alternativas [...] (CAMPOS, 2003, p. 106)

Nesta perspectiva, pode-se observar experiências que procuram integrar formação e atuação profissional. A Estratégia Saúde da Família (ESF), por exemplo, requer uma atuação junto às comunidades que implica no enfrentamento de

4. Cabe destacar o Programa Nacional de Reorientação Profissional em Saúde (Pró-Saúde) e o Programa de Educação pelo Trabalho em Saúde (PET-Saúde) como iniciativas que traduzem as mudanças no que se refere à formação e educação no âmbito da graduação em saúde. 
problemas que excedem os de ordem biológica e individual. Pagani e Andrade (20 I 2) apresentam, com base na experiência da cidade de Sobral/CE, um novo profissional, o preceptor de território, que na UBS assume o papel de um educador permanente de saúde. Para desenvolver suas atividades precisa "conhecer bem a realidade epidemiológica, social, cultural e política do seu território e estar sempre próximo dos residentes e da equipe no desenvolvimento do processo de trabalho, bem como no que diz respeito à organização e gestão dos serviços" (PAGANI; ANDRADE, 20|2, p. 99).

Outro exemplo pode ser as iniciativas desenvolvidas no Programa de Educação pelo Trabalho em Saúde (PET-Saúde). Ferreira et al. (20।2) relatam o envolvimento de equipes de Saúde da Família e alunos de medicina e enfermagem do PET-Saúde da Universidade Estadual de Santa Cruz, no combate à dengue. A experiência foi positiva para o serviço, para o reconhecimento de necessidades de saúde bem como para a qualificação da formação dos graduandos. Delfino et al. (20 I 2) avaliaram, do ponto de vista dos usuários do SUS, a interferência de docentes e alunos de uma universidade de Santa Catarina sobre a saúde e a qualidade de vida, e concluíram que houve melhoria na assistência, na qualidade da atenção e, sobretudo, nos processos de ensino-aprendizagem mais humanizados e participativos.

Na educação física, a participação de estudantes no PET-Saúde tem originado relatos interessantes, como os de Bernardoni e Carvalho (20 I 2) e Prado (20 I 2). $\bigcirc$ primeiro trabalho mostra um projeto de intervenção com dança de contato e improvisação visando intervir nos limites e possibilidades dos corpos em movimento e, ao mesmo tempo, promover encontros que instiguem mudanças na qualidade das relações entre usuários e profissionais de saúde; o segundo, descreve duas intervenções que contaram com a participação de estudantes de educação física enfatizando o trabalho multiprofissional e interdisciplinar a partir de intervenções em UBS, assim como a atuação em diferentes territórios. São trabalhos que problematizam o distanciamento entre a formação em educação física e a realidade do SUS e ressaltam o PET-Saúde como estratégia que qualifica a formação porque agrega as subjetividades que se produzem permanentemente entre estudantes, docentes, profissionais e usuários.

As políticas públicas de saúde, seja na dimensão da formação, seja na da intervenção, têm importância fundamental nos modos de pensar e agir em saúde no Brasil. E, no caso da educação física, as mudanças já são visíveis especialmente no que se refere às práticas corporais. A PNPS (BRASIL, 2006a), por exemplo, sugere que às pc/af aconteçam na rede básica de saúde e na comunidade, e traz orientações, entre outras, como:

[... ] mapear e apoiar as ações de práticas corporais/atividade física existentes nos serviços de atenção básica e Estratégia de Saúde da Família e inserir naqueles onde não há ações; 
ofertar práticas corporais/atividade física como caminhadas, prescrição de exercícios, práticas lúdicas, esportivas e de lazer, na rede básica de saúde, voltadas tanto para a comunidade como um todo quanto para grupos vulneráveis [...].

No entanto, a compreensão dessa relação ainda carrega traços do modelo mecanicista, no qual a saúde está pautada nas Ciências Naturais e o corpo é visto de forma fragmentada e destituído de subjetividade, que podem ser percebidos tanto nos âmbitos da formação e da pesquisa como no da intervenção (CARVALHO, 200 I; FENSTERSEIFER, 2006). Todavia, o saber requerido do profissional é cada vez mais interdisciplinar e suas funções dizem respeito também à questão da administração e gestão do trabalho, além da perspectiva técnica (CARVALHO, 200I).

Neste sentido, Fensterseifer (2006) alerta que é preciso evitar na educação física, a reprodução de modelos "aplicacionistas" que acabam criando uma relação instrumental em que o profissional é sujeito e o aluno é objeto. Para o autor, é necessário agregar a contribuição das Ciências Humanas e da Filosofia, uma vez que atuamos com pessoas e suas subjetividades e não somente com a dimensão física dos corpos. Desse modo, a intervenção do profissional de saúde, "[... ] mesmo que no espaço da clínica, passa a assumir uma dimensão ético-política distinta à medida que configura outra possibilidade de mundo, na qual, espera-se, as pessoas sejam respeitadas em suas queixas, dores, prazeres e histórias [...]" (FENSTERSEIFER, 2006, p. 100).

Como, então, pensar a formação do profissional de saúde? Como conduzi-la? Feuerwerker (2003), a partir de experiências voltadas para a mudança na formação desses profissionais, observa que as práticas profissionais organizadas com base nas necessidades de saúde da população é o ponto central para fortalecer e integrar processos educativos: articulando conteúdos, campos disciplinares distintos e as contribuições da área social.

Para Pinheiro e Ceccim (2005, p. 19), a formação deve compreender movimentos que envolvem:

primeiro, o empreendimento ético-político de pensar a formação como educação permanente, colocando o cotidiano do trabalho e os impactos do trabalho sobre o processo saúde-doença nas coletividades como critério de contemporaneidade dos cursos às necessidades sociais e científicas em saúde; e, segundo a centralidade da integralidade em saúde como uma noção constitutiva de saberes e práticas com potência para superar a modelagem do ensino e dos serviços centrados em procedimentos, com os usuários interpretados [...] como simples território onde evoluem os quadros fisiopatológicos.

Partimos do pressuposto que a formação é um processo dinâmico, que permanentemente se transforma e que acolhe saberes e práticas que se constituem no 
cotidiano, no enfrentamento dos problemas de saúde, considerando as subjetividades, ou "[...] toda e qualquer manifestação dos Sujeitos viventes" (CAMPOS, 2007, p. 5 I). É nesse contexto que as práticas de saúde e a gestão são entendidas como capazes de alterar os padrões de subjetividade e a maneira como as pessoas intervêm diante das diferentes questões relacionadas à saúde, o que permite compreender o potencial "pedagógico e terapêutico do trabalho em saúde" (CAMPOS, 2000, p. I 4).

Pensar como a educação física articula-se com as outras profissões da saúde nas equipes de referência, ${ }^{5}$ por exemplo, e como tem orientado o trabalho na atenção básica, é fundamental para encontrarmos caminhos mais condizentes para formar e atuar no sentido de favorecer as mudanças. Transformações exigem conhecimento teórico e prático que norteie o trabalho profissional, com base nos princípios do SUS; uma concepção de saúde que contemple a complexidade do campo; efetiva aproximação entre ensino e serviço; e responda às necessidades de saúde da população.

Integralidade, um dos princípios do SUS, na educação física se reduz à ideia do "sujeito integral". Ainda que não seja unanimidade a definição no campo da saúde coletiva, integralidade é "[...] parte de uma imagem objetivo, um enunciado de certas características do sistema de saúde, de suas instituições e de suas práticas [...] um conjunto de valores pelos quais vale lutar, pois se relacionam a um ideal de uma sociedade mais justa e mais solidária" (MATTOS, 2006, p. 4I). Assim, a adoção de referencial teórico-metodológico relacionado a outros modos de gerir e planejar o trabalho em saúde é fundamental para que os "modelos" de intervenção na educação física sejam avaliados e ressignificados.

\section{CLÍNICA AMPLIADA E TRABALHO EM SAÚDE: UM CAMINHO...}

Como visto, apesar das propostas de mudança, o modelo que orienta a formação profissional na área da saúde ainda é fortemente pautado pela dimensão técnica e pela perspectiva biologicista de saúde-doença. Pensar no trabalho em saúde requer outros modelos, e uma das propostas que repercutem no campo da saúde coletiva é apresentada por $\operatorname{Campos}^{6}$ (2000, 2003).

O referido autor tece uma crítica ao modo como a clínica é praticada tradicionalmente, e busca reformulá-la e reinventá-la na Clínica Ampliada. Questiona a

5. A equipe de referência é um rearranjo organizacional que busca deslocar o poder das profissões e corporações de especialistas, reforçando o poder de gestão da equipe interdisciplinar. Ela é composta por distintos especialistas e profissionais encarregados de intervir sobre um mesmo objeto: problemas de saúde (CAMPOS; DOMITTI, 2007).

6. Este autor desenvolveu teorias e métodos que discutem e reorientam o trabalho em saúde, vinculado ao grupo de pesquisa da Faculdade de Medicina Preventiva da Unicamp. É importante ressaltar também que vários de seus estudos são permeados de experiências de atuação e formação nesse âmbito. 
padronização, a programação e o planejamento sustentado nas regularidades, nas certezas e que, portanto, não consegue conviver com a imprevisibilidade da vida cotidiana. A Clínica Ampliada busca superar a fragmentação entre biologia, subjetividade e sociabilidade, operando com projetos terapêuticos complexos, deslocando o Sujeito ${ }^{7}$ envolvido nas políticas e práticas de saúde para primeiro plano.

Para Campos (2003), a reforma da clínica moderna deve superar o foco exclusivo sobre a doença, direcionando-o para o Sujeito que, além de possuir uma biografia singular, manifesta no seu corpo a enfermidade ou o sofrimento em contexto particular. Assim, na Clínica Ampliada há uma nova dialética entre Sujeito e doença. Há uma reconfiguração do objeto de saber e da clínica: enfermidade, Sujeito e seu contexto são tomados como objetos de estudo/conhecimento e de intervenção (CAMPOS, 2003). O trabalho em saúde, assim, pode ser compreendido como um "neoartesanato", desenvolvido em rede, processualmente, considerando que há "[...] singularidade dos casos no trabalho em saúde, o que exige improvisação e criatividade em ato: clínica da fusão de paradigmas e protocolos" (CAMPOS, 20 I 0, p. 2343).

Mas então, como seria trabalhar e lidar com essa dialética, com a imprevisibilidade do trabalho em saúde? Primeiramente, o autor mostra que é preciso reconhecer os limites dos saberes estruturados e, depois, acompanhar os aspectos genéricos do processo saúde-doença. É preciso aprender com as variações. Outro aspecto importante é praticar a escuta e o decidir compartilhado (ouvindo usuários e outros profissionais, expondo dúvidas).

Especificamente no que se refere à Clínica Ampliada em equipes de Saúde da Família, Campos (2003) indica que a construção de vínculos entre pacientes, famílias, comunidade e profissionais pode ser um dos meios para se desenvolver um trabalho com qualidade. A construção de vínculo depende do modo como as equipes se responsabilizam pela saúde das pessoas de uma microrregião e de como se encarregam dos casos específicos.

Nesse sentido, a construção de vínculos pode ser compreendida como um recurso capaz de ampliar as ações dos profissionais de saúde, o que permite o enfrentamento do desafio de efetivamente investir na educação em saúde, na conversa e na escuta e nas práticas em grupos. O êxito das ações, portanto, está implicado com a constituição de iniciativas compartilhadas entre profissionais e usuários, e não apenas com o desenvolvimento da dimensão técnica do trabalho (CAMPOS, 2003).

Cunha (2007) também trata da Clínica Ampliada, com base em experiências e referências que dizem respeito a modelos de atenção e de gestão, especialmente

7. A palavra Sujeito está escrita em letra maiúscula para denotar seu entendimento contrário à noção de objeto, isto é, como o ser em sua potencialidade, que exerce e não somente sofre uma ação. 
os propostos por Campos. $\bigcirc$ autor destaca que o modelo de gestão do trabalho interfere diretamente tanto nos resultados das ações como no envolvimento das equipes. E propõe, como um dos objetivos do trabalho em saúde, privilegiar um equilíbrio dinâmico entre autonomia e controle, objetividade e subjetividade, benefícios e danos, tanto na relação clínica quanto na gerencial.

O referido autor desenvolve uma análise crítica das formas tradicionais de gestão (os protocolos, a programação em saúde e a medicina baseada em evidências), apontando a pretensão totalizante e a ausência de diálogo na clínica como fatores que comprometem a qualidade da atenção básica. A partir dessas considerações, discute e apresenta novos instrumentos para a construção da Clínica Ampliada, especificamente para este nível assistencial.

O principal instrumento proposto por Cunha (2007) é o antiprotocolo. Este seria o resultado da mediação entre a teoria da Clínica Ampliada e a cogestão ${ }^{8} \mathrm{com}$ a realidade singular do SUS. Ele é composto de três movimentos: o diagnóstico, a escolha dos recursos possíveis e a assimilação das diretrizes para a Clínica Ampliada.

São considerados recursos tanto as terapêuticas (remédios, exames, consultas) como outras atividades da equipe. No entanto, o autor alerta que não é possível dizer a priori, para uma equipe singular e sua clientela, qual é o recurso mais importante, no sentido de que a decisão deve vir da cogestão.

Com relação aos saberes, destaca a importância do reconhecimento das singularidades de cada Sujeito trabalhador e dos seus saberes, de modo que todos possam contribuir com os processos terapêuticos e com os resultados finais, o que contribui para relativizar a hierarquia profissional/universitária socialmente construída. ${ }^{9}$ Questiona, portanto, os filtros teóricos tradicionais (anamnese) e chama a atenção para a necessidade de os profissionais estarem mais atentos às falas dos Sujeitos, dando espaço para ideias e palavras dos pacientes, o que favoreceria a própria análise destes sobre suas condições (CUNHA, 2007).

\section{APROXIMAÇÕES COM A EDUCAÇÃO FÍSICA}

Identificamos, na atualidade, duas grandes tendências na educação física no que diz respeito ao referencial teórico-conceitual e metodológico que orienta os saberes e práticas na atenção básica em saúde: uma mais biomédica (KOKUBUN et al., 2007; MONTEIRO et al., 2007; GUIMARÃES et al., 2008; SIQUEIRA

8. Na cogestão a tarefa de gerir passa a ser coletiva e não mais de uma minoria dominante (CAMPOS, 2000).

9. Minelli, Soriano e Fávero (2009) realizaram estudo em uma clínica sobre o trabalho em equipes multiprofissionais, incluindo o profissional de Educação Física, e observaram a complexidade das interações profissionais como a subordinação à área dominante (medicina) e a hierarquização das profissões "secundárias" no setor da saúde. 
et al., 2008; COSTA; BOTCHER; KOKUBUN, 2009; MENDONÇA; TOSCANO; OLIVEIRA, 2009; MELLO et al., 20I0; BIELEMANN; KNUTH; HELLAL, 20 I0; NAKAMURA, et al. 20I0; SILVA et al., 20l I) e outra que agrega estudos que resultam de uma articulação entre a educação física e a saúde coletiva (WACHS; MALAVOLTA, 2005; CARVALHO; FREITAS, 2006; WARSCHAUER et al., 2007; WACHS; FRAGA, 2009; WARSCHAUER; D'URSO, 2009; ABIB et al., 20I0; WACHS et al., 20 I0) privilegiando modos de intervir baseados no acolhimento, na produção de novos padrões de subjetividade, no vínculo, na não segmentação das intervenções por condição clínica, de gênero ou ainda de faixa etária, na autonomia, bem como no trabalho com os sujeitos adoecidos em detrimento do foco nas doenças. Propostas na área específica da Clínica Ampliada encontramos somente o trabalho de MENDES (20 I 3), referido anteriormente. No entanto, não podemos deixar de mencionar que essa é uma questão muito presente na literatura no campo da saúde coletiva, assim como os problemas e desafios enfrentados no cotidiano do trabalho na atenção básica à saúde que são mais "familiares" aos profissionais que tradicionalmente atuam no SUS.

É também por esse motivo que propusemos o tema. A atividade física indicada para hipertensos, obesos e diabéticos, hoje muitas vezes conduzida por profissionais de educação física na UBS, pode ser considerada um elemento complicador, haja vista os profissionais enfatizarem a doença e o componente técnico da prática, não raras vezes desconsiderando as necessidades de saúde das pessoas, que inclui a compreensão sobre os determinantes sociais, assim como os fatores que envolvem o processo saúde-doença-intervenção (CARVALHO, 2006) e, em última instância, a produção de saúde.

Uso predominante de guidelines e protocolos como instrumentos do trabalho em saúde (CUNHA, 2007) pode ser outro exemplo, e se associa, de certa forma, ao discurso que se tem na educação física: para alcançar bons resultados com a atividade física é preciso identificar a prática mais indicada para melhorar a saúde (orgânica), e a frequência e intensidade mais adequadas a partir de classificações e padrões previamente definidos. Nessa condição o profissional de educação física assume uma postura semelhante a do "médico".

O tema da utilização dos protocolos de forma crítica pode ser problematizado quando considerado o recente movimento "Exercise is medicine", que remete à discussão feita por Fraga (2006) acerca da nova "racionalidade físico-sanitária" que é imposta à sociedade na atualidade. Esta realidade pode ser identificada, por exemplo, na iniciativa do Centro de Estudos do Laboratório de Aptidão Física de São Caetano do Sul (CELAFISCS), desenvolvida em parceria com o Colégio Americano de Medicina Esportiva (ACSM), que lança mão de ações de promoção da saúde por meio da ampla defesa da recomendação por parte dos profissionais de saúde à 
prática de atividade física pela população, sob supervisão do profissional de educação física, mas que, no entanto, evidencia um movimento impositivo, normalizador e corporativista de pensar a saúde, próprios do modelo biomédico.

O desafio reside em repensar um "saber-fazer" estruturado/institucionalizado, particularmente no que se refere aos protocolos de atividades visando à prevenção e ao tratamento de doenças, como hipertensão e diabetes. Muitas vezes há um descompasso entre o saber técnico e o que os Sujeitos definem como necessidade de saúde, ou ainda como eles lidam e reinventam saberes e práticas diante da realidade e de seus projetos de vida.

Castellani Filho e Carvalho (2006) consideram que movimentar-se implica em conhecer os limites e possibilidades em várias dimensões - intelectual e afetiva e não só biológica e física. É preciso, para tanto, "experimentar essa diversidade e poder expressá-la no sentido de planejar e implementar as ações de modo partilhado, sobretudo com a comunidade, percebendo seu 'movimento' como processo" (CASTELLANI FILHO; CARVALHO, 2006, p. 2 I 8). Dessa forma, pode-se romper com o predomínio da técnica e com a atitude autoritária e impositiva do profissional que não se coloca na perspectiva do outro.

Gomes, Pich e Vaz (2006) argumentam que atualmente os indivíduos enfrentam diferentes desafios e oportunidades em relação ao seu corpo e a sua saúde em termos de informação, produtos e serviços. Especificamente no campo da educação física notam que há um processo de ampliação do conhecimento que também gera diferentes práticas e discursos sobre a saúde que, por sua vez, leva a sensação de dúvida e incerteza sobre o que é "ser saudável". Cria-se um contexto no qual o indivíduo tem que decidir sobre o que está disponibilizado e se responsabilizar por suas escolhas, que podem ser mais ou menos determinadas pela força da indústria cultural (GOMES; PICH; VAZ, 2006).

Fraga (2006) investigou o exercício da informação por meio do programa "Agita São Paulo" e chama a atenção para a reconstrução da retórica sobre a vida ativa nos últimos anos e da própria relação entre educação física e saúde. A ideia da vida ativa tem influenciado a atuação dos profissionais da área que tem privilegiado modelos de intervenção de caráter prescritivo e culpabilizador condizente com uma lógica físico-sanitária, como parte "[...] de uma rede mundial de disseminação da atividade física como fator de proteção contra o sedentarismo" (FRAGA, 2006, p. 8).

Ainda segundo Fraga (2006), é fundamental que os profissionais da educação física compreendam a lógica universalista e as articulações políticas e econômicas que fundamentam os modelos com o propósito de empreenderem uma análise sobre as implicações do exercício da informação no que diz respeito ao processo de regulação e governo dos corpos no "mercado da vida ativa".

É dessa forma, portanto, que ocorre a propagação de visões normativas e unilaterais que seguem a tendência do padrão hegemônico sobre a saúde, o corpo 
e as práticas corporais dissociada dos sujeitos e sua cultura, e/ou que minimizam suas possibilidades de mudança e criação.

Porém, existem direcionamentos metodológicos que se contrapõem à tradição positivista da área da saúde, nos quais há envolvimento maior das pessoas e que buscam "aumentar a potência de intervenção dos vários agrupamentos envolvidos diante de um problema sanitário relevante: a equipe técnica, o grupo vulnerável, a comunidade, movimentos, organizações, instituições, etc." (CAMPOS, 2003, p. 26).

A Clínica Ampliada pode ser uma contrapartida à medida que "cada pessoa ou cada agrupamento também interferem de modo ativo na produção de saúde ou doença", além dos fatores sociais, econômicos e do funcionamento dos próprios serviços de saúde. Para potencializar essa condição, entretanto, é relevante ter " [...] uma sustentação teórica de modelos de atenção voltados para reconhecer e para construir esse papel ativo dos usuários na produção da própria saúde ou doença" (CAMPOS, 2003, p. 107).

Nesse sentido é uma teoria que pode qualificar o profissional de educação física à medida que exige noções e conceitos e, sobretudo, uma atitude propositiva e problematizadora que se funda na complexidade das relações que se constituem e se renovam permanentemente no processo de trabalho e chamam a atenção para os obstáculos e conflitos a serem enfrentados, haja vista a formação em saúde valorizar a epidemiologia do risco, o modelo clínico-prescritivo e a racionalidade biomédica no processo saúde-doença.

A Clínica Ampliada contribui nas intervenções com pc/afà medida que exige dos profissionais o reconhecimento da produção de saúde como dinâmica; compromisso com a atenção básica que demanda, por sua vez, capacidade do profissional para lidar com a complexidade das relações (sujeitos, famílias, equipe de saúde) e com a própria organização das instituições; da necessidade de aprimoramento da capacidade de lidar com as incertezas e frustrações decorrentes dos encontros em saúde, que sempre são singulares, considerando a necessidade de apoiar as pessoas para lidarem com suas dificuldades e limitações visando a produção do cuidado de maneira contextualizada.

Nessa direção, os trabalhos que fazem uma aproximação com a teoria da Clínica Ampliada em outras áreas da saúde, citados anteriormente, indicam a atualidade do tema também na educação física. E é nesse contexto que chamamos a atenção para a necessidade de qualificar estudantes e profissionais da área, a fim de que possam reconhecer outras teorias e metodologias que considerem a diversidade de caminhos relacionados com a produção de cuidado, uma vez que a intervenção implica também responder às necessidades das pessoas e coletivos e, sobretudo, rever as iniciativas objetivadoras e moralistas e seus efeitos no contexto das práticas de saúde. 
Assim, é premente refazermos caminhos, aproximando formação profissional e intervenção. Os saberes e práticas de saúde são vias transversais que se transformam e produzem redes e se alimentam de experiências. Essa complexidade faz do trabalho em saúde, do enfrentamento dos desafios e da busca por soluções um movimento contínuo que pode acontecer na formação e no cotidiano do trabalho com base no pressuposto de que vivemos e fazemos nossos modos de viver, o tempo todo, em relação.

Physical Education and Health: Approximations with Amplified Clinic

ABSTRACT: This text presents reflexive thoughts related to physical education from the point of view of the professional formation and of the work in health, with the objective to relate these aspects with the theoretic-conceptual and methodological framework of the Amplified Clinic. The formation and work addresses to the insertion and development of physical education in the field of health including the public policies. However, grounding of formation and professional intervention is lacking as far as going beyond the biological perspective. Thus, the Amplified Clinic can make a counterpoint offering subsidies to strengthen the dialogue with other health professionals in actions oriented to horizontal relations and in the approximation among the professional, service and users of SUS.

KEYWORDS: Physical Education; Amplified Clinic; professional formation; work in health.

\section{Educación física y salud: aproximaciones con la clínica ampliada}

RESUMEN: Este texto presenta reflexiones a respeto de la educación física del punto de vista de la formación profesional y del trabajo en salud, con el fin de relacionar a lo referencial teórico-conceptual y metodológico de la Clínica Ampliada. Formación y trabajo remete a una inserción y un desarrollo de la educación física en el campo de la salud, incluso en el ámbito de las políticas públicas. Entretanto, observase ausencia de fundamentación en la formación y intervención profesional más allá de la perspectiva biológica. En este sentido, la Clínica Ampliada puede ser un contrapunto: ofrece subsidios en los diálogos con otras profesiones, en las acciones orientadas por medio de relaciones más horizontales y en la aproximación entre profesional especifico, servicio y usuarios de lo SUS.

PALABRAS CLAVE: Educación física; clínica ampliada; formación profesional; trabajo en salud.

\section{REFERÊNCIAS}

ABIB, L. T. et al. Práticas corporais em cena na saúde mental: potencialidades de uma oficina de futebol em um centro de atenção psicossocial de Porto Alegre. Pensar a Prática, Goiânia, v. 13, n. 2, p. I-15, 2010.

AYRES, J. R. C. M. O cuidado, os modos de ser (do) humano e as práticas de saúde. Saúde e Sociedade, São Paulo, v. 13, n. 3, p. 16-29, set./dez. 2004. 
BERNARDONI, G.; CARVALHO, Y. M. Práticas corporais, dança de contato e improvisação como ferramentas de integralidade - um relato de experiência na UBS Paulo VI. In: CONGRESSO BRASILEIRO DE SAÚDE COLETIVA, 10., 2012, Porto Alegre. Anais ... Porto Alegre, 2012. Disponível em: <http://aconteceeventos.sigevent.com.br/anaissaudecoletiva >. Acesso em: 4 jan. 2013.

BIELEMANN, R. M.; KNUTH, A. G.; HALLAL, P. C. Atividade física e redução de custos por doenças crônicas ao sistema único de saúde. Revista Brasileira de Atividade Física e Saúde, Londrina, v. I5, n. I, p. 9-15, 2010.

BRASIL. Ministério da Saúde. Secretaria de Atenção à Saúde. Política Nacional de Promoção da Saúde (PNPS). Brasília, 2006a. Disponível em: < http://www.portal.saude.gov.br/portal/ arquivos/pdf/portaria687_2006_anexol.pdf>. Acesso em: 19 jan. 20 I I.

BRASIL. Ministério da Saúde. Secretaria de Atenção à Saúde. Política Nacional de Práticas Integrativas e Complementares no SUS. Brasília, 2006b. Disponível em: < http://bvsmc.saude. gov.br/bvs/publicacoes/pnpic.pdf>. Acesso em: 18 maio 201 I.

BRASIL. Portaria n I54, de 24 de janeiro de 2008. Cria os núcleos de apoio à saúde da família NASF. Diário Oficial da União, Poder Executivo, Brasília, DF, 25 jan. 2008. Seção I, n. I8, p. 47.

BRASIL. Portaria n ${ }^{\circ} 719$, de 7 de abril de 201 I Institui a criação do programa academia da saúde no âmbito do sistema único de saúde. Diário Oficial da União, Poder Executivo, Brasília, DF, 8 abr. 201 I. Seção I, n. 68, p. 52.

CAMPOS, G. W. S. Um método para análise e co-gestão de coletivos. São Paulo: Hucitec, 2000.

CAMPOS, G. W. S. Saúde paidéia. São Paulo: Hucitec, 2003.

CAMPOS, G. W. S. Clínica e saúde coletiva compartilhadas: teoria paidéia e reformulação ampliada do trabalho em saúde. In: CAMPOS, G. W. S. (Org.). Tratado de saúde coletiva. São Paulo: Hucitec, Rio de Janeiro: Fiocruz, 2007. p. 4I-80.

CAMPOS, G. W. S. Cogestão e neoartesanato: elementos conceituais para repensar o trabalho em saúde combinando responsabilidade e autonomia. Ciência \& Saúde Coletiva, Rio de Janeiro, v. I5, n. 5, p. 2337-2344, ago. 2010.

CAMPOS, G. W. S.; DOMITTI, A. C. Apoio matricial e equipe de referência: uma metodologia para gestão do trabalho interdisciplinar em saúde. Cadernos de Saúde Pública, Rio de Janeiro, v. 23, n. 2, p. 399-407, fev. 2007.

CARVALHO, Y. M. Atividade física e saúde: onde está e quem é o sujeito da relação? Revista Brasileira de Ciências do Esporte, Campinas, v. 22, n. 2, p. 9-21, jan. 2001.

CARVALHO, Y. M. Promoção da Saúde, práticas corporais e atenção básica. Revista de Saúde Família, Brasília, v. 2, n. 7, p. 33-35, jul./set. 2006.

CARVALHO, Y. M.; CECCIM, R. B. Formação e educação em saúde: aprendizados com a saúde coletiva. In: CAMPOS, G. W. S. (Org.). Tratado de saúde coletiva. São Paulo: Hucitec, Rio de Janeiro: Fiocruz, 2007. p 137-170. 
CARVALHO, Y. M.; FREITAS, F. F. Atividade física, saúde e comunidade. Cadernos Saúde Coletiva, Rio de Janeiro, v. I4, n. 3, p. 489-505, jul./set. 2006.

CASTELLANI FILHO, L.; CARVALHO, Y. M. Ressignificando o esporte e o lazer nas relações com a saúde. In: CASTRO, A.; MALO, M. (Org.). SUS: ressignificando a promoção da saúde. São Paulo: Hucitec, 2006. p. 208-222.

CECCIM, R. B.; FEUERWERKER, L. Mudança na graduação das profissões de saúde sob o eixo da integralidade. Cadernos de Saúde Pública, Rio de Janeiro, v. 20, n. 5, p. I400- I0, set./out. 2004.

COSTA, B. V.; BOTTCHER, L. B.; KOKUBUN, E. Aderência a um programa de atividade física e fatores associados. Motriz, Rio Claro, v. I 5, n. I, p.25-36, jan./mar. 2009.

CUNHA, G. T. Antiprotocolo: uma proposta de co-gestão para a clínica ampliada. São Paulo: Hucitec, 2007.

DELFINO, M. R. R. Repercussões do processo de ensinar-aprender em serviços de saúde na qualidade de vida dos usuários. Trabalho, educação e saúde, Rio de Janeiro, v. 10, n. 2, out. 20 I2. Disponível em: <http://mww.scielo.br/scielo.php?script=sci_arttext\&pid=S| $98 \mid$ 774620 I $2000200008 \&$ lng =en\&nrm=iso > . Acesso em: 21 dez. 2012.

DEMÉTRIO, F. et al. A nutrição clínica ampliada e a humanização da relação nutricionista-paciente: contribuições para reflexão. Revista de Nutrição, Campinas, v. 24, n. 5, p.743-763, set./out. 201 I .

FENSTERSEIFER, P. E. Corporeidade e formação do profissional na área da saúde. Revista Brasileira de Ciências do Esporte, Campinas, v. 27, n. 3, p. 93-102, maio 2006.

FERREIRA, V. S. et al. PET-Saúde: uma experiência prática de integração ensino-serviço-comunidade. Revista Brasileira de Educação Médica, Rio de Janeiro, v. 36, n. I , supl. 2, p. |47- I 5 I, mar. 2012 . Disponível em: <http://www.scielo.br/scielo.php?script=sci_arttext\&pid=SO 00 -5502201200030002 l \&lng=en\&nrm=iso >. Acesso em: 21 dez. 2012.

FEUERWERKER, L. Reflexões sobre as experiências de mudança na formação dos profissionais de saúde. Olho Mágico, Londrina, v. 10, n. 3, p. 21-26, jul./set. 2003.

FRAGA, A. B. Exercício da informação: governo dos corpos no mercado da vida ativa. Campinas: Autores Associados, 2006.

GARIGLIO, M. T.; RADICCHI, A. L. A. O modo de inserção do médico no processo produtivo em saúde: o caso das unidades básicas de Belo Horizonte. Ciência \& Saúde Coletiva, Rio de Janeiro, v. I3, n. I, p. I53-63, jan./fev. 2008.

GOMES, I. M.; PICH, S.; VAZ, A. F. Sobre algumas vicissitudes da noção de saúde na sociedade dos consumidores. Revista Brasileira de Ciências do Esporte, Campinas, v. 27, n. 3, p. 153- |68, maio 2006.

GUIMARÃES, A. C. et al. Efeitos de um programa de atividade física sobre o nível de autonomia de idosos participantes do programa de saúde da família. Fitness \& Performance Journal, Rio de Janeiro, v. 7, n. I, p. 5-9, jan./fev. 2008. 
KOKUBUN, E. et al. Programa de atividade física em unidades básicas de saúde: relato de experiência no município de Rio Claro. Revista Brasileira de Atividade Física e Saúde, Londrina, v. I2, n. I, p.45-50, 2007.

MALFITANO, A. P. S. Campos e núcleos de intervenção na terapia ocupacional social. Revista de Terapia Ocupacional. São Paulo, v. 16, n. I, p. I-8, jan./abr. 2005.

MINELLI, D. S.; SORIANO, J. B.; FÁVERO, P. E. O profissional de educação física e a intervenção em equipes multiprofissionais. Movimento, Porto Alegre, v. I 5, n. 4, p. 35-62, out./dez. 2009.

MATTOS, R. Os sentidos da integralidade: algumas reflexões acerca de valores que merecem ser defendidos. In: PINHEIRO, R.; MATTOS, R. A. (Org.). Os sentidos da integralidade na atenção e no cuidado à saúde. Rio de Janeiro: ABRASCO, 2006. p. 39-64 .

MATUMOTO, S. et al. A prática clínica do enfermeiro na atenção básica: um processo em construção. Revista Latino-Americana de Enfermagem, Ribeirão Preto, v. 19, n. I , p. 1 23- | 30, jan./fev. 201 I .

MELLO, D. et al. Efeitos de um programa de caminhada sobre parâmetros biofísicos de muIheres com sobrepeso assistidas pelo Programa de Saúde da Família (PSF). Revista Brasileira de Atividade Física e Saúde, Londrina, v. I 5, n. 4, p. 224-228, 2010.

MENDES, V. M. As práticas corporais e a clínica ampliada: a educação física na atenção básica. 2013. 178 f. Dissertação (Mestrado em Ciências) - Escola de Educação Física e Esporte, Universidade de São Paulo, São Paulo, 2013.

MENDONÇA B. C. A.; TOSCANO, J. J. O.; OLIVEIRA, A. C. C. Do diagnóstico à ação: experiências em promoção da atividade física programa academia da cidade Aracaju: promovendo saúde por meio da atividade física. Revista Brasileira de Atividade Física \& Saúde, Florianópolis, v. 14, n. 3, p. 21 |-216, 2009.

MONTEIRO, H. L. et al. Efetividade de um programa de exercícios no condicionamento físico, perfil metabólico e pressão arterial de pacientes hipertensos. Revista Brasileira de Medicina do Esporte, Niterói, v. 13, n. 2, p. 107-1 12, mar./abr. 2007.

NAKAMURA P. M. et al. Programa de intervenção para a prática de atividade física: Saúde Ativa Rio Claro. Revista Brasileira de Atividade Física \& Saúde, Londrina, v. I 5, n. 2, p. I 28- | 32, 2010.

NASCIMENTO, D. D. G.; OLIVEIRA, M. A. C. Reflexões sobre as competências profissionais para o processo de trabalho nos Núcleos de Apoio à Saúde da Família. O Mundo da Saúde, São Paulo, v. 34, n. I, p. 92-96, jan./mar. 2010.

ONOCKO CAMPOS, R. Reflexões sobre o conceito de humanização em saúde. Saúde em Debate, Rio de Janeiro, v. 27, n. 64, p. 123-130, maio/ago. 2003.

PAGANI, R.; ANDRADE, L. O. M. Preceptoria de território, novas práticas e saberes na estratégia de educação permanente em saúde da família: o estudo do caso de Sobral, CE. Saúde e Sociedade, São Paulo, v. 21, supl. I, p. 94-106. 2012. Disponível em: http://www.scielo.br/pdf/sausoc/v2Isl/08.pdf. Acesso em: 28 maio 2012. 
PINHEIRO, R.; CECCIM, R. B. Experimentação, formação, cuidado e conhecimento em saúde: articulando concepções, percepções e sensações para efetivar o ensino da integralidade. In: PINHEIROS, R. (Org.). Ensinar saúde: a integralidade e o SUS nos cursos de graduação na área da saúde. Rio de Janeiro: ABRASCO, 2005. p. 13-33.

PINTO, J. C. S. G. Integralidade, clínica ampliada e transdisciplinaridade: conceitos para a potencialização das práticas em saúde mental. 2007. 216 f. Dissertação (Mestrado em Psicologia) - Universidade Federal Fluminense, Niterói, 2007.

PRADO, A. R. PET-Saúde - USP: as experiências dos estudantes de educação física. In: CONGRESSO BRASILEIRO DE SAÚDE COLETIVA, 10, 2012, Porto Alegre. Anais eletrônicos... Porto Alegre: 2012. Disponível em <http://aconteceeventos.sigevent.com.br/ anaissaudecoletiva $>$. Acesso em: 4 jan. 2013.

SANTOS, A. M.; ASSIS, M. M. A. Da fragmentação à integralidade: construindo e (des) construindo a prática de saúde bucal no Programa de Saúde da Família (PSF) de Alagoinhas, BA. Ciência \& Saúde Coletiva, Rio de janeiro, v. I I , n. I, p. 53-6I , jan./mar. 2006.

SILVA, M. P. et al. Programa multidisciplinar para promoção da saúde envolvendo atividade física supervisionada: ações do PAFIPNES na atenção à saúde de mulheres em uma Unidade Básica de Saúde de São José do Rio Pardo-SP. Revista Brasileira de Atividade Física \& Saúde, Londrina, v. I6, n. 3, p. 362-366, 201 I.

SIQUEIRA, F. V. et al. Atividade física em adultos e idosos residentes em áreas de abrangência de unidades básicas de saúde de municípios das regiões Sul e Nordeste do Brasil. Cadernos Saúde Pública, Rio de Janeiro, v. 24, n. I, p. 39-54, jan. 2008.

VASCONCELOS, C. M.; PASCHE, D. F. O sistema único de saúde. In: CAMPOS, G. W. S. et al. (Org.). Tratado de saúde coletiva. São Paulo: Hucitec; Rio de Janeiro: Fiocruz, 2007. p. $53 \mid-562$.

WACHS, F. et al. Processos de subjetivação e territórios de vida: o trabalho de transição do hospital psiquiátrico para serviços residenciais terapêuticos. Physis, Rio de Janeiro, v. 20, n. 3, p. 895-912, 2010.

WACHS, F; FRAGA, A. B. Educação Física em centros de atenção psicossocial. Revista Brasileira de Ciências do Esporte, Campinas, v. 3 I , n. I , p. 93-107, set. 2009.

WACHS, F; MALAVOLTA. M. A. Pode ser a oficina de corporeidade uma alternativa terapêutica na saúde mental? Boletim da Saúde, Porto Alegre, v. 19, n. 2, p. 13-20, jul./dez. 2005.

WARSCHAUER, M. et al. As escolhas das práticas corporais e dos profissionais que as conduzem nas unidades básicas de saúde do distrito Butantã-SP. In: CONGRESSO BRASILEIRO DE CIÊNCIAS DO ESPORTE E CONGRESSO INTERNACIONAL DE CIÊNCIAS DO ESPORTE, I 5.; CONGRESSO INTERNACIONAL DE CIÊNCIAS DO ESPORTE, 2., 2007, Recife. Anais eletronicos... Disponível em: <http//:www.cbce.org.br/resumos/003. pdf. >. Acesso em: 29 nov. 2010. 
WARSCHAUER, M.; D'URSO, L. Ambiência e formação de grupo em programa de caminhada. Saúde e Sociedade, São Paulo, v. I 8, supl. 2, p. 104-107, abr.jun. 2009.

Recebido em: 07 fev. 2012 Aprovado em: 10 dez. 2012

Endereço para correspondência: Fabiana Fernandes de Freitas Av. Presidente Vargas, 1759

Bairro: Carmo Araraquara-SP CEP: | 4800-005 